\section{More work needed in examining the relationship between mean platelet volume and inflammation in varicocele pathophysiology}

\author{
Zafer Demirer, MD;* Ali Uğur Uslu, MD**
}

*Department of Urology, Eskisehir Military Hospital, Eskisehir/Turkey; ${ }^{*}$ Department of Internal Medicine, Eskisehir Military Hospital, Eskisehir/Turkey

Cite as: Can Urol Assoc J 2015;(9-10):E639. http://dx.doi.org/10.5489/cuaj.3114 Published online September 9, 2015.

W e read with great interest the article by Coban and colleagues. ${ }^{1}$ In this well-designed study, Coban and colleagues evaluate the relationship between varicocele and the mean platelet volume (MPV), mean corpuscular volume, platelet, and platelet distribution width (PDW). They found that MPV increased in patients with varicocele and inclined to decrease again after the varicocele was surgically corrected. A recognizable increase was also available in PDW, but it was not statistically important. The ready presence of these markers at no additional cost may increase their wider use in clinical practice.

Varicoceles are present in $15 \%$ to $20 \%$ of the normal male population and in about $35 \%$ to $40 \%$ of men with infertility. ${ }^{2}$ Varicocele is associated with other vascular pathologies. ${ }^{3,4}$ The pathogenesis of varicocele is retrograde flow into the spermatic vein. The superiority of experimental data from clinical and animal models indicate a detrimental effect of varicoceles on spermatogenesis. ${ }^{2}$ Testicular temperature elevation and venous reflux play a significant role in varicocele-induced testicular dysfunction, although the exact pathophysiology of varicocele-induced harm is not completely understood. ${ }^{2}$ Varicocele stimulates an inflammatory event that could play a harmful role in spermatogenesis. ${ }^{5-7}$

MPV is a widely used laboratory marker associated with platelet function based on inflammatory conditions. Increased levels of MPV were shown in varicocele, ${ }^{8-9}$ cerebrovascular disease, peripheral artery disease, stroke, malignancy, ulcerative colitis, and coeliac disease - all related to endothelial dysfunction on the basis of inflammation. ${ }^{10,11}$ IL-1, IL- 6 and TNF- $\alpha$ are among the progenitor cytokines that impress the platelet manufacturer. Higher MPV values are also a useful indicator of higher thromboycte activity. ${ }^{12}$ The level of platelets is increased in high-grade inflammation, leading to a reduction in the MPV level as a result of the migration of most large reactive platelets to inflammatory sites and intensive consumption of these platelets. In cases of low-grade inflammation, an increase in MPV level occurs as a result of the increased reactive immature platelets. ${ }^{12}$ MPV is potential subclinical inflammation marker in patients with familial Mediterranean fever..$^{13,14}$

An important limitation of this study was the relatively small number of patients as varicocele affects about $20 \%$ to $25 \%$ of the male population. Consequently, MPV, IL-1, IL-6, IL- 8 and TNF- $\alpha$ are easy ways to evaluate the relation varicocele pathophysiology and the relevant vascular pathologies. We believe the findings of the current study will lead to further studies examining the relationship between MPV and varicocele.

Competing interests: The authors all declare no competing financial or personal interests.

\section{References}

1. Coban S, Keles I, Biyik I, et al. Does varicocele correction lead to normalization of preoperatively elevated mean platelet volume levels? Can Urol Assoc J 2015;9:E5-9. http://dx.doi.org/10.5489/cuaj.2113

2. Kessler A, Meirsdorf $S$, Graif $M$, et al. Intratesticular varicocele: Gray scale and color doppler sonographic appearance. J Ultrasound Med 2005;24:1711-16.

3. Androulakis AE, Katsaros AA, Kartalis AN, et al. Varicose veins are common in patients with coronary artery ectasia. Just a coincidence or a systemic deficit of the vascular wall? Eur J Vasc Endovasc Surg 2004;27:519-24. http://dx.doi.org/10.1016/i.ejvs.2004.02.023

4. Yetkin E, Kilic S, Acikgoz N, et al. Increased prevalence of varicocele in patients with coronary artery ectasia. Coron Artery Dis 2005; 16:261-4. http://dx.doi.org/10.1097/00019501-200508000-00001

5. Habibi B, Seifi B, Mougahi SM, et al. Increases in interleukin-6 and interferon-gamma levels is progressive in immature rats with varicocele. Ir J Med Sci 2015;184:531-7. http://dx.doi.org/10.1007/ s11845-014-1167-3

6. Nallella KP, Allamaneni SS, Pasqualotto FF, et al. Relationship of interleukin-6 with semen characteristics and oxidative stress in patients with varicocele. Urology 2004;64:1010-3. http://dx.doi.org/10.1016/i. urology.2004.05.045

7. Moretti E, Collodel G, Mazzi L, et al. Resistin, interleukin-6, tumor necrosis factor-alpha, and human semen parameters in the presence of leukocytospermia, smoking habit, and varicocele. Fertil Steril 2014;102:354-60. http://dx.doi.org/10.1016/ifertnstert.2014.04.017

8. Bozkurt Y, Soylemez H, Sancaktutar AA, et al. Relationship between mean platelet volume and varicocele: A preliminary study. Urology 2012;79:1048-51. http://dx.doi.org/10.1016/i.urology.2012.01.019

9. Coban S, Keles I, Biyik I, et al. Is there any relationship between mean platelet volume and varicocele? Andrologia 2015:47:37-41. http://dx.doi.org/10.1111/and.12220

10. Balta $S$, Demirkol $S$, Unlu $M$, et al. Other inflammatory markers should be kept in mind when assessing the mean platelet volume. Platelets 2014;25:552-3. http://dx.doi.org/10.3109/09537104.201 3.775643

11. Demirkol S, Balta S, Unlu M, et al. Neutrophils/lymphocytes ratio in patients with cardiac syndrome $X$ and its association with carotid intima-media thickness. Clin Appl Thromb Hemost 2014;20:250-5. http:// dx.doi.org/10.1177/1076029612467227

12. Gasparyan AY, Ayvazyan L, Mikhailidis DP, et al. Mean platelet volume: A link between thrombosis and inflammation? Curr Pharm Des 2011;17:47-58. http://dx.doi.org/10.2174/138161211795049804

13. Özer S, Yılmaz R, Sönmezgöz E, et al. Simple markers for subclinical inflammation in patients with Familial Mediterranean Fever. Med Sci Monit 2015;23:298-303.

14. Sakall $\mathrm{H}$, Kal 0 . Mean platelet volume as a potential predictor of proteinuria and amyloidosis in familial Mediterranean fever. Clin Rheumato/ 2013;32:1185-90. http://dx.doi.org/10.1007/s10067-013-2257-8

Correspondence: Dr. Zafer Demirer, Department of Urology, Eskisehir Military Hospital, Eskisehir/ Turkey; zaferdemirer@mynet.com 